\title{
Murraya koenigii
}

\author{
Satish Chand Saini*, Dr. GBS Reddy
}

Shri Venkateshwara University, NH -24, Rajabpur, Gajraula, Distt. Amroha, Pin Code No. 244236 (UP) Ph No +91-8859500757, 8859500741, Telefax No :+91-0592-229123,www.svu.edu.in, mail: info@svu.edu.in

\begin{abstract}
Medicinal plants or their bioactive compounds have been utilized by developing countries for primary and traditional healthcare system since very long period of time. In several ancient systems of medicine including Ayurveda, Siddha and Unani, Murraya koenigii, a medicinally important herb from mainly Asian origin has vast number of therapeutic applications such as in bronchial disorders, piles, vomiting, skin diseases etc. The medicinal utilities have been described especially for leaf, stem, bark and oil. The well studied pharmacology and phytochemistry of M. koenigii and therapeutic potential of this plant needs to be compiled in form of review. The present review incorporates the description of M. koenigii, its phytochemical constituents and various pharmacological activities of isolated compounds as well as bioactivity of extract studies carried out by various numbers of laboratories. In addition to that, it highlights its potential to be the important nutraceutical for diabetes and cardioprotection.

Plants have been used in traditional medicine for several thousand years. India is perhaps the largest producer of medicinal herbs and is rightly called the "Botanical garden of the World". Murraya koenigii commonly known as Meethi neem, belongs to the family Rutaceae. The curry tree is native to India and it is found almost everywhere in the Indian subcontinent excluding the higher levels of Himalayas. Curry leaves used traditionally as antiemetic, antidiarrhoeal, febrifuge and blood purifier. The whole plant is considered to be a tonic and stomachic.

Curry leaves is found to be effective as antioxidant, antidiabetic, antibacterial, antihypertensive, cytotoxic and also in the treatment of bronchial respiratory difficulties. The leaves are used traditionally as spice in curry and other eatables. The aim of the present review study is to update information about pharmacognostical, phytochemical and pharmacological studies of Murraya koenigii.
\end{abstract}

Key Words: Murraya koenigii, phytochemistry, biological activity, Rutaceae, medicine, Ayurvedic, plant extracts, review

\section{Introduction}

Murraya koenigii, commonly known as curry leaf or kari patta in Indian dialects, belonging to Family Rutaceae which represent more than 150 genera and 1600 species $^{1}$. Murraya Koenigii is a highly values plant for its characteristic aroma and medicinal value. It is an important export commondity from India as it fetches good foreign revenue. A number of chemical constituents from every part of the plant have been extracted. The most important chemical constitutents responsible for its intense characteristic aroma are P-gurjunene, Pcaryophyllene, P-elemene and O-phellandrene. The plant is rich source fof carbazole alkaloids ${ }^{2}$. Bioactive coumarins, acridine alkaloids and carbazole alkaloids from family Rutaceae were reviewed by Ito $^{3}$. M. koenigii is widely used in Indian cookery for centuries and have a versatile role to play in traditional medicine. The plant is credited with tonic and stomachic properties. Bark and roots are used as stimulant and externally to cure eruptions and bites of poisonous animals. Green leaves are eaten raw for cure of dysentery, diarrhoea and for checking vomiting. Leaves and roots are also used traditionally as bitter, anthelmintic, analgesic, curing piles, inflammation, itching and are useful in leucoderma and blood disorders ${ }^{4,5}$. Several systematic scientific studies are also being conducted regarding the efficacy of whole plant or its parts in different extract forms for the treatment of different diseases. M. koenigii contains a number of chemical constituents that interact in a complex way to elicit their pharmacodynamic response. A number of active constituents responsible for the medicinal properties have been isolated and characterized. This plant has been reported to have anti-oxidative, cytotoxic, antimicrobial, antibacterial, anti ulcer, positive inotropic and cholesterol reducing activities ${ }^{6-10}$. Therefore the present review summarizes the available literature till date on isolation of phytoconstituents, biological activities of the isolated compounds and pharmacological actions of extracts along with the clinical studies.

Murraya koenigii (Rutaceae) commonly known as Meethi neem, is an aromatic more or less deciduous shrub or a small tree up to $6 \mathrm{~m}$ in height found throughout India up to an altitude of $1500 \mathrm{~m}$ and are cultivated for its aromatic leaves ${ }^{11}$. In traditional system of Medicine, it is used as antiemetic, antidiarrhoeal, dysentery, febrifuge, blood purifier, tonic, stomachic, flavoring agent in curries and chetneys. The oil is used externally for bruises, eruption, in soap and perfume industry ${ }^{12}$. The phytoconstituents isolated so far from the leaves are alkaloids viz., mahanine ${ }^{13}$, koenine, koenigine, koenidine ${ }^{14}$, girinimbiol, girinimibine ${ }^{15}$, koenimbine, O-methyl 
murrayamine A, O-methyl mahanine, isomahanine, bismahanine, bispyrayafoline ${ }^{16}$ and other phytoconstituents such as coumarin glycoside viz., scopotin, murrayanine ${ }^{17}$, calcium, phosphorus, iron, thiamine, riboflavin, niacin, vitamin $\mathrm{C}$, carotene and oxalic acid. The essential oil from leaves yielded di- alpha phellandrene, Dsabinene, D-_-pinene, dipentene,

D- -terpinol and caryophyllene ${ }^{18}$. It is reported to possess antioxiant, antibacterial, antifungal, larvicidal, anticarcinogenic, hypoglycemic, anti-lipid peroxidative, hypolipidemic and antihypertensive activity ${ }^{19}$. It is also reported to contain 5,8-dimethyl furanocoumarin, 1-al, 3[6', 6' dimethyl 5-hexene] carbazole and _-sitosterol ${ }^{20}$.

\section{Plant Description and habitat}

The plant is distributed and cultivated throughout India. It is found wild from Himalaya's, Uttarakhand, Sikkim to Garhwal, Bengal, Assam, Western Ghats and Travancore- Cochin. Propagation is done by seeds, which germinate freely under partial shade. Is also available in other part of Asian region like in moist forests of 500-1600 m height in Guangdong, S Hainan, S Yunnan (Xishuangbanna), Bhutan, Laos, Nepal, Pakistan, Sri Lanka, Thailand, Vietnam. Together with South Indian immigrants, curry leaves reached Malaysia, South Africa and Réunion island. Outside the Indian sphere of influence, they are rarely found. M. koenigii is an unarmed, semi deciduous aromatic shrub or small tree with slender but strong woody stem and branches covered with dark grey bark, leaves are imparipinnate, glabrous, and very strongly aromatic. Leaflets $9-25$ or more, short stalked, alternate, gland dotted and strongly aromatic. The stem of M. koenigii is an aromatic and more or less deciduous shrub or small tree upto 6 meters in height and 15 to $40 \mathrm{~cm}$ in diameter ${ }^{21}$. The main stem is dark green to brownish. The bark of the stem can be peeled off longitudinally which exposes the white wood underneath. Flowers are small, white fragrant ebracteate, calyx deeply five cleft, pubescent. Petals five, free, whitish, glabrous and with dotted glands. Fruits occur in close clusters, small ovoid or sub-globose, glandular, thin pericarp enclosing one or two seeds having spinach green color ${ }^{22}$.

\section{Traditional Uses:}

Fresh leaves, dried leaf powder, and essential oil are widely used for flavouring soups, curries, fish and meat dishes, eggs dishes, traditional curry powder blends, seasoning and ready to use other food preparations. The essential oil is also utilized by soap and cosmetic aromatherapy industry ${ }^{23}$. Curry leaves are boiled with coconut oil till they are reduced to blanked residue which is then used as an excellent hair tonic for retaining natural hair tone and stimulating hair growth. It is traditionally used as a whole or in parts as antiemetics, antidiarrheal, febrifuge, blood purifier, antifungal, depressant, anti-inflammatory, body aches, for kidney pain and vomiting. ${ }^{24-32}$.

\section{Pharmacological Studies \\ Antibacterial activity}

The essential oil from M. koenigii leaves showed antibacterial effect against B. subtilis, Staph. aureus, C. pyogenes, P. vulgaris and Pasteurella multicida. The pure oil was active against the first three organisms even at a dilution of $1: 500^{33}$.

The acetone extract of the fresh leaves of M. koenigii on fractionation gives three bioactive carbazole alkaloids named as mahanimbine, murrayanol and mahanine, which has shown mosquitocidal, antimicrobial and topisomerase I and II inhibition activities ${ }^{34}$

\section{Antifungal activity}

The essential oil from leaves of M. koenigii showed antifungal activity against C. albicans, C. tropicalis, A. niger, A. fumigatus and Microsporum gypseum. It was effective against C. albicans even at a dilution of 1:500. The ethanolic extract of the leaves showed fungitoxicity against Colletotrichum falcatum and Rhizoctonia solani ${ }^{35}$.

The ethanolic extract of the roots and also the whole plant excluding roots of M. koenigii, however, did not show any antifungal activity against Cryptococcus neoformans, Trichophyton mentagrophytes and Microsporum canis ${ }^{36,37}$.

Aqueous and ethanolic extracts of M. koenigii were evaluated for the anti candidal activity against the 30 candida albicans, in that no extract exhibited any anticandidal activity ${ }^{38}$.

\section{Antiprotozoal activity}

Ethanolic extracts (50\%) of Murraya koenigii whole plant excluding roots (extract A) and roots alone (extract B) were screened for their pharmacological actions. Extract A showed antiprotozoal action against Ent. Histolytica, antispasmodic effect on isolated guinea pig ileum, whereas extract B showed antiprotozoal activity against Ent. Histolytica and as well as antihypertensive activity in cat $/ \operatorname{dog}^{39}$. 
Table 1- Active compounds of Murraya koenigii and their activities

\begin{tabular}{|c|c|c|}
\hline Murraya koenigii compounds & Source & Biological activity \\
\hline Lutein & Leaves & Antioxidant activity \\
\hline \multirow{2}{*}{ Tocopherol } & Leaves & Antioxidant activity \\
\hline & Leaves & Hepatoprotective \\
\hline Carotene & Leaves & Antioxidant activity \\
\hline Koenimbine & Leaves & Antioxidant activity \\
\hline Isomahanine & Leaves & Anti caries \\
\hline Mahanine & Stem and bark & Antimicrobial \\
\hline \multirow{2}{*}{ Murrayanol } & Leaves & Mosquitocidal \\
\hline & Leaves & Anti-microbial \\
\hline Murrayanine & Stem bark & Anti fungal \\
\hline \multirow{3}{*}{ Girinimbine } & Stem bark & Anti-cancer \\
\hline & Stem bark & Anti fungal and antibactearial \\
\hline & Leaves & Hepatoprotective \\
\hline
\end{tabular}

\section{Conclusion}

Keeping in view the tremendous pharmacological activities and availability of literature, M. koenigii may be utilized to alleviate the symptoms of variety of diseases as evident from the pre-clinical data. Although crude extract from various parts of $\mathrm{M}$. koenigii have numerous medical applications, modern drugs can be developed after extensive investigation of its bioactivity, mechanism of action, pharmaco-therapeutics, toxicity and after proper standardization and clinical trials. The available literature and wide spread availability of $\mathrm{M}$. koenigii in India thus makes it an attractive candidate for further pre-clinical and clinical research.

\section{Acknowledgement}

The authors are highly thankful to the management of Herbal Research and Development Institute (HRDI),Selaqui, Dehradun (UK) India and Management of Samarth Analytical Laboratory, Nasik (MH), India for providing necessary facilities.

\section{References}

[1]. Satyavati GV, Gupta AK, Tendon N, Medicinal Plants of India, Vol-2, Indian council of medical research, New Delhi India, $1987,289-299$

[2]. Kumar VS, Sharma A, Tiwari R, Sushil K. Murraya Koenigii-a review, JMAPS 1999

[3]. Ito C. Studies On Medicinal Resources of Rutaceous Plants And Development To Pharmaceutical Chemistry, Natural Med. 2000; 54: 117-122.

[4]. Nadkarni KM, Indian Materia Medica, Edition 3, Vol. I, Popular Prakashan, Mumbai, 1976, 196.

[5]. Kirtikar KR, Basu BD. Indian Medicinal Plants, Edition 2, Vol. I, Oriental Enterprises, Uttarchal Pradesh, $1981,473$.

[6]. Ram HNA, Hatapakki BC, Hukkeri IV, Aryavaidyan J. 2002; 16 (1), 40-44.

[7]. The Wealth of India, Council of Scientific and Industrial Research, New Delhi, 2003, 317.

[8]. Manfred F, John MP, Dajaja DS, Douglas AK. Koenoline, a further cytotoxic carbazole alkaloid from Murraya koenigii. Phytochemistry, 1985; 24:3041-3043.

[9]. Shrinivasan K. Plant foods in the management of diabetes mellitus: spices as beneficial antidiabetic food adjuncts. Int. J. Food Sci. Nutr. 2005; 56(6): 399-414.

[10]. Shah KJ, Juvekar AR. Positive inotropic effect of Murraya koenigii (Linn.) Spreng extract on an isolated perfused frog heart. Indian Journal of Experimental Biology, 2006; 44:481 - 484.

[11]. Anonymous, The Wealth of India: A Dictionary of Indian Raw Materials and Industrial Products.Publication \& Information Directorate, New Delhi :CSIR, 1998:446-448.

[12]. Prajapati ND, Purohit SS, Sharma AK, Kumar T. A Handbook of Medicinal Plants. Jodhpur: Agrobios,2003: $352-353$.

[13]. Narasimhan NS, Paradkar MV, Kelkar SL.Alkaloids of Murraya koenigi, Structures of mahanine, koenine, koenigine and koenidine. Indian J Chem 1970; 8:473-476.275.

[14]. Narasimhan NS, Paradkar MV, Chitguppi VP,Kelkar SL. Alkaloids of Murraya koenigi, Structures of mahanimbine, koenimbine, mahanine, koenine, koenigine and koenidine. Indian J Chem 1975; 13: 993-995.

[15]. Adebajo AC, Avoola OF, Iwalewa EO,Akindahunsi AA, Omisore NO, Cadewunmi CO et al.Anti-trichomonal, biochemical and toxicological activities of methanolic extract and some carbazole alkaloids isolated from the leaves of Murraya koenigii growing in Nigeria. Phytomedicine 2006; 13(4): 246-54.

[16]. Tachibana Y, Kikuzaki H, Lajis NH, Nakatani N. Comparison of antioxidative properties of carbazole.

[17]. Adebajo AC, Reisch J: Minor furocoumarins of Murraya koenigii. Fitoterpia 2000; 71(3): 334-7.

[18]. Gopalan C, Rama Shastri BV, Balasubramanian SC. Nutritive value of Indian Foods. New Delhi:ICMR, 1984: 66,117.

[19]. Iyer D, Uma DP. Phyto-pharmacology of Murraya koenigii. Pharmacognosy Reviews 2008; 2: $180-184$.

[20]. Sumit Gupta, Padmaa M Paarakh, Usha Gavani. Isolation of Phytoconstituents from the leaves of Murraya koenigii Linn. Journal of Pharmacy Research 2009, 2(8),1313-1314.

[21]. An update on Murayya Koenigii S: a multifunctional Ayurvedic herb. Journal of Chinese integrative medicine. 2012; 9(8):824-833.

[22]. Raghunathan K, Mitra R, Pharmacognosy Of Indigenous Drugs, Central Council For Research In Ayurveda And Siddha, New Delhi, Vol. I: 433.

[23]. G.L. Gupta and S.S. Nigam. Chemical examination of the leaves of Murraya koenigii. Planta Med. 19: 83 (1970).

[24]. Adebajo AC, Olayiwola G, Verspohl EJ, Iwalewa EO, Omisore NOA, Bergenthal D, et.al. Evaluation of the ethnomedical claims of Murraya koenigii. Pharm Biol. 2004; 42(8): 610-620. 
[25]. Ponnusamy S, Ravindran R, Zinjarde S, Bhargava S, Ravi Kumar A. Evaluation of traditional Indian antidiabetic medicinal plants for human pancreatic amylase inhibitory effect in vitro. Evid Based Complement Alternat Med. Epub 2010 Sep 23

[26]. Chakrabarty M, Nath A, Khasnobis S, Chakrabarty M, Konda Y, Harigaya Y, Komiyama K. Carbazole alkaloids from Murraya koenigii. Phytochemistry. 1997; 46(4) : 751-755.

[27]. Nutan MTH, Hasnat A, Rashid MA. Antibacterial and cytotoxic activities of Murraya koenigii. Fitoterapia, $1998 ; 69(2): 173-175$.

[28]. Iyer UM, Mani UV. Studies on the effect of curry leaves supplementation (Murraya koenigi) on lipid profile, glycated proteins and amino acids in non-insulin-dependent diabetic patients. Plant Foods Hum Nutr. 1990; 40(4) : 275-282.

[29]. Purohit SS, Sharma AK, Prajapati ND, Kumar T. A handbook of medicinal plants: a complete source book. Edition 2. Jodhpur: Agrobios (India). 2009, 352-353.

[30]. Kumar VS, Sharma A, Tiwari R, Kumar S. Murraya koenigii (curry leaf): a review. J Med Arom Plant Sci. 1999; 21(4) : 11391141.

[31]. Rana VS, Juyal JP, Rashmi, Blazquez MA. Chemical constituents of the volatile oil of Murraya koenigii leaves. Int J Aromather, 2004; 14(1): 23-25.

[32]. Rao BRR, Rajput DK, Mallavarapu GR. Chemical diversity in curry leaf (Murraya koenigii) essential oils. Food Chem, 2011; 126(3): 989-994.

[33]. Goutam MP, Purohit RM. Antimicrobial activity of the essential oil of the leaves of Murraya koenigii. Indian J. Pharm 1974; 36:11.

[34]. Narasimhan NS, Paradkar MV, Chitguppi VP, Kelkar SL. Alkaloids of Murraya koenigi, Structures of mahanimbine, koenimbine, mahanine, koenine, koenigine and koenidine. Indian J. Chem 1975; 13: 993.

[35]. Kishore N, Dubey NK, Tripathi RD, Singh SK. Fungitoxic activity of leaves of some higher plants. Natl. Acad. Sci. Lett 1982; 5(1): 9.

[36]. Singh L, Sharma M. Antifungal properties of some plant extracts. Geobios 1978; 5(2):49.

[37]. Garg SC. Antifungal activity of the essential oils. Indian J. Pharm1974; 36:46.

[38]. Vaijayanthimala J, Anandi C, Udhava V, Pugalendi KV. Anticandididal activity of certain South Indian medicinal plants. Phytother Res 2000; 14(3): 207-9.

[39]. Bhakuni DS, Dhar ML, Dhar MM, Dhawan BN,Gupta B, Mehrotra BN. Screening of Indian Plants for biological activity. Indian J. Exp. Biol 1969; 7:250. 